\title{
The Effect of an Inspiratory Muscle Training Period at High Altitude on Arterial Oxygen Saturation and Performance of Iran's National Team Endurance Runners
}

\section{Mohamadi Mirzaei Roohollah* and Mirdar Shadmehr}

Mazandran University, Babolsar, Iran

\begin{abstract}
The aim of this study was to investigate the effect of inspiratory muscle training at high altitude on peripheral capillary oxygen saturation and performance among endurance runners. Twelve endurance male runners (age: 24 yrs \pm 3 yrs, height: $180.5 \mathrm{~cm} \pm 4.2 \mathrm{~cm}$, weight: $66.7 \mathrm{~kg} \pm 3 \mathrm{~kg}$, Body mass index: $20.5 \pm 1.0$ ) among Iranian national team were randomly divided into case and control group in hypoxic condition. Exhaustive testing free $1500 \mathrm{~m}$, strength Index and arterial oxygen saturation tests were taken before and $24 \mathrm{~h}$ after training period. Training program include same continues, interval, aerobic and resistance training for two groups. Runners performed 16 training session per week in high altitude within four weeks. Data were analyzed by analysis of variance $(P \leq 0.05)$. Inspiratory muscle training at hypoxia due to significant decrease in $1500 \mathrm{~m}$ running performance, inspiratory muscle strength and peak inspiratory flow in both group, but the differences in volume and peripheral capillary oxygen saturation were not significant $(P \leq$ 0.05).

This study suggests that using inspiratory muscle training along with specified training in hypoxia increases inspiratory muscle strength and peak inspiratory flow pressure meanwhile it decreases ventilation and $1500 \mathrm{~m}$ running time in lower altitude.
\end{abstract}

Keywords: Respiratory muscle training; Hypoxia; Peripheral capillary oxygen saturation $\left(\mathrm{SpO}_{2}\right)$; Endurance performance

\section{Introduction}

Competition drives athletes to continually seek new ways to gain the edge over their fellow competitors. Historically, training for high performance has focused on rigorous peripheral muscle and cardiovascular training using partial or full-body exercises. Respiratory muscle training (RMT) and particularly inspiratory muscle training (IMT) have been investigated as a method which athletes could improve their performance [1]. Mechanisms postulated to explain improved sport performance from IMT are decreases in the rating of perceived breathlessness (RPB) or rating of perceived exertion (RPE) and attenuation of the metaboreflex phenomenon that may result in the redirection of blood flow from the locomotor muscles to respiratory muscles [2-5].

Evidence is emerging that respiratory muscles fatigue may affect exercise performance via metaboreflex [6,7]. Accumulation of metabolites such as lactic acid in respiratory muscles activates group III and especially group IV nerve afferents which ultimately triggers brain sympathetic outflow increase and causes vasoconstriction in exercising limbs $[8,9]$.

Improved aerobic capacity of primary and accessory respiration muscles has reported amongst athletes likely during IMT/RMT because of enhanced aerobic metabolism and oxygen delivery. This in turn may have delayed the onset of fatigue and reduced competitive blood flow between the exercising respiratory and limb muscles during sport performance. There is some evidence that specific training of respiratory muscles can attenuate the respiratory muscle metaboreflex $[10,11]$.

In consequence, a certain similarity between the stresses induced in the human body by altitude exposure and by a maximal intensity specific training can be deduced [12-24]. Switching phosphofructokinase gene expression to anaerobic pathway and increased energy production via anaerobic pathways as a compensatory mechanism for the reduced energy supplied by aerobic pathways [16]. The most plausible explanation for IMT-induced performance adaptations probably lies within the reports of reduced effort sensations and increasing $\mathrm{SpO}_{2}$ at altitude [25,26]. It is therefore surprising that experimental models examining the effects of IMT have tended to do so in isolation rather than utilising IMT as an additional aid to a hypoxia training programme [23]. We have previously proposed that the inclusion of IMT within a training programme might positively alter the perception of effort during training bouts and consequently augment the ventilation parameters and quality of work accomplished. This in turn could be expected to enhance endurance performance [24]. Several studies previously have suggested that inclusion of IMT within a training program might positively improves respiratory indexes including oxygen partial pressure $\left(\mathrm{PaO}_{2}\right)$, peripheral capillary oxygen saturation $\left(\mathrm{SpO}_{2}\right)$, hemoglobin oxygen saturation $\left(\mathrm{SaO}_{2}\right)$, and Endurance performance. This consequently augments the volume and quality of accomplished work [12-27]. This study has conducted to investigate whether IMT would significantly increase the magnitude of arterial saturation experienced at rest and improve $1500 \mathrm{~m}$ performance at $2500 \mathrm{~m}$ altitude.

\section{Methods and Materials}

Twelve endurance male runners among Iranian national team were randomly divided into case and control group in hypoxic conditions agreed to participate in this study (Table1). All procedures were approved by the institutional ethics committee (Olympic committee letter number 2634). We ensured that there was no evidence of respiratory cardiovascular or infection diseases, diabetes. Allergy,

*Corresponding author: Mohamadi Mirzaei Roohollah, Mazandran University, Babolsar, Iran, Tel: +989352152011; E-mail: coach.iri@gmail.com

Received: May 13, 2016; Accepted: June 22, 2016; Published: June 25, 2016

Citation: Roohollah MM, Shadmehr M (2016) The Effect of an Inspiratory Muscle Training Period at High Altitude on Arterial Oxygen Saturation and Performance of Iran's National Team Endurance Runners. J Pulm Respir Med 6: 356 doi:10.4172/2161-105X.1000356

Copyright: (c) 2016 Roohollah MM, et al. This is an open-access article distributed under the terms of the Creative Commons Attribution License, which permits unrestricted use, distribution, and reproduction in any medium, provided the original author and source are credited. 


\begin{tabular}{|c|c|c|c|c|}
\hline & \multicolumn{2}{|c|}{ EXP (n=6) } & \multicolumn{2}{c|}{ CON (n=6) } \\
\hline Parameter & Pre- altitude & Post-altitude & Pre- altitude & Post- altitude \\
\hline Age & $2.8 \pm 23.1$ & $2.8 \pm 23.1$ & $3.1 \pm 25.6$ & $3.1 \pm 25.6$ \\
\hline Height (cm) & $4.0 \pm 178.3$ & $4.0 \pm 178.3$ & $3.3 \pm 182.6$ & $3.3 \pm 182.6$ \\
\hline Body mass (kg) & $3.1 \pm 67.5$ & $2.6 \pm 66.1$ & $3.8 \pm 66.0$ & $3.4 \pm 65.5$ \\
\hline BMI (kg.m $\left.{ }^{2}\right)$ & $0.3 \pm 21.2$ & $0.4 \pm 20.8$ & $1 \pm 20.7$ & $1 \pm 19.7$ \\
\hline
\end{tabular}

Table 1: Pre- and post-altitude anthropometric characteristics of the subjects in the Experimental $(E X P)$ and in the Control $(C O N)$ groups (mean $\pm S D)$.

smoking or supplemental use were other excluding criterion. Written consents were taken from all participants.

\section{Experimental design}

Study was conducted after competitive season and during their period of rest. First, all participants were called to Olympic camp for checking their height, weight, body mass index (BMI). After getting familiar with Power Breath device (K5 model, UK) and SPIROLAB pulse oximeter device (MIR, Italy) they were randomly divided to experimental group (EXP) $(n=6)$ and placebo or control group $(\mathrm{CON})$ $(\mathrm{n}=6)$. Then functional performances in $1500 \mathrm{~m}$ were taken place in $200 \mathrm{~m}$ standard indoor track at $1400 \mathrm{~m}$ altitude from both groups. Power Breath was used for inspiratory indexes measurement such as maximum inspiratory pressure (MIP) and peak inspiratory flow (PIF) as well as inspiratory volume. $\mathrm{SpO}_{2}$ in altitude was measured by pulse oximeter. Then Runners performed special training by $\mathrm{R} 2 \mathrm{M}$ method at $2500 \mathrm{~m}$ altitude in Delfan camp at Zagros Mountain. They trained in combinational sessions including endurance, speed, power and plyometric trainings with different volumes and intensities. All inspiratory indexes were measured and $1500 \mathrm{~m}$ executive function performance test were taken right $24 \mathrm{~h}$ after the end of the forth week. Field trainings such as altitude living-training and live high train high (LHTH) were done (Table 2).

\section{Inspiratory muscle training}

First of all, we measured the maximum muscular power $(\mathrm{cm}$ $\mathrm{H}_{2} \mathrm{O}$ ) for an inspiration (S-Index) which is considered equal with MIP. Training protocol was considered including thirty deep inspirations with closed nose with Power Breath device for EXP group within seven days.

\section{Altitude training intervention}

All participants performed the altitude program. Similar training program such as interval, aerobic and resistance training have been conducted for both groups. The runners performed 16 training session per week within four weeks in high altitude (just three tracks training sessions per week at seven days performed at low altitude). $\mathrm{SpO}_{2}$ measurement was carried out only in altitude at least for three minutes in flat position and just during night time.

\section{Data collection and statistical analyses}

Data were collected and analyzed by SPSS software (version 21.0, SPSS, Chicago, Illinois) parametric data assumptions were met (Shapiro-Wilks test), pre training, post training and group interactions results were statistically compared using two-ways repeated measures analyses of variance (ANOVA) and post hoc Bonferroni tests of Honestly Significant Difference as appropriate. Probability values of less than 0.05 were considered significant. All results were expressed as mean standard deviation (SD) unless otherwise stated.

\section{Results}

Results driven by ANOVA repeated measurements of altitude's effect on variables along with between-group factor revealed that despite of group and training protocol type, $1500 \mathrm{~m}$ running time performance showed significant difference $(\mathrm{T}=838 / 65, \mathrm{P}=0 / 01)$. Post hoc Bonferroni test showed significant difference $(1 \%)$ between experiment group and control group $(\mathrm{p} \leq 0.05)$. Statistical assessment of S-Index $(\mathrm{T}=26 / 13$, $\mathrm{P}=0 / 01)$ and $\mathrm{PIF}(\mathrm{T}=7 / 33, \mathrm{P}=0 / 02)$ showed significant difference in duration of being exposed to Altitude condition $(\mathrm{P} \leq 0.05)$. But no significant differences between groups was indicated by post hoc Bonferroni tests $(\mathrm{P} \leq 0.05)$. Results also indicated that excepting $\mathrm{SpO}_{2}(\mathrm{~T}=1 / 31, \mathrm{P}=0 / 27)$ and Volume $(\mathrm{T}=0 / 643, \mathrm{P}=0 / 44)$ there were no significant difference in other variables in both groups $(\mathrm{P} \geq 0.05)$ (Table 3 and Figures 1-3).

\section{Discussion}

Current study mainly shows that IMT significantly increased inspiratory muscle strength (S-Index) and PIF (EXP $=18.48 \%$, $\mathrm{CON}=15.60 \%)$. At the same time it significantly decreased $1500 \mathrm{~m}$ running time after hypoxic period. Even though significant differences of between-group S-Index and PIF were expected, but there were no statistical significant differences in these cases. These findings are consistent with results of McConnell [28] and Kilding et al. [29] studies and show inconsistency with Nicks et al. [30] and Wylegala et al. [31] results. McConnell [28] and Kilding et al. [29] showed that S-Index and PIF had been improved by IMT in every sport filed excepting snorkeling and swimming. The main reason for not being effective on swimmers might be related to water pressure on their chest during exercise. Besides, elite swimmers may have reached to their own optimum level of respiratory muscle functioning therefore they won't increase their PIF after IMT anymore.

Our study indicated the importance of exposure to hypoxia despite of IMT device impact for both groups. Hypoxia itself can cause hyperventilation, tachypnea and consequently hyper-respiratory function, so muscular endurance will be improved as result of higher blood flow. Brown et al. [32] have reported significant increase of S-Index and PIF fifty male after IMT which is admitting the results of current study. According to Brown et al. [33,34] study skeletal and respiratory muscle's endurance decrease in older age and respiratory muscle alterations in elderly people are similar with musculoskeletal changes during weight training. Nicks [30] has reported the same result. He has suggested the reason of better outcomes amongst rowers might be related to physiological and mechanical nature of their exercise.

It is pertinent to mention that not only the main respiratory muscles and accessories are deploying for ventilation during rowing but also they have considerable role in terms of stabilizing the chest and transferring the force throughout the paddling process. These dual demands from respiratory muscles creates respiratory pattern for keeping performance for rowers [30]. This shows a close relation between running and rowing as both need frequent constrictions along with high intensity.

We didn't observe any alteration in $\mathrm{SpO}_{2}$ during relax time after IMT in hypoxic condition. Downey et al. [22] have assessed IMT effect on physiological variables and observed $\mathrm{SpO}_{2}$ alterations in hypoxic condition. Mitch Lomax [20] has obtained about $6 \% \mathrm{O}_{2}$ Sat in 4880 $\mathrm{m}$ and $5550 \mathrm{~m}$ altitudes among his study group. This is not admitting the results of current study. Because $\mathrm{SpO}_{2}$ decreases in higher altitude this inconsistency might be due to higher altitude in Mitch Lomax [20] study. On one hand, being in high altitude enhances $\mathrm{SpO}_{2}$ and on the other hand it decreases at higher altitude than $2500 \mathrm{~m}$, so the reason of not changing $\mathrm{SpO} 2$ can be justified in this way. 
Citation: Roohollah MM, Shadmehr M (2016) The Effect of an Inspiratory Muscle Training Period at High Altitude on Arterial Oxygen Saturation and Performance of Iran's National Team Endurance Runners. J Pulm Respir Med 6: 356. doi:10.4172/2161-105X.1000356

\begin{tabular}{|c|c|c|c|c|c|c|c|}
\hline \multirow{5}{*}{ Training load } & Very high & & & & & & \\
\hline & high & & & & & & \\
\hline & Medium & & & & & & \\
\hline & low & & & & & & \\
\hline & Very low & & & & & & \\
\hline Training Intensity & & & $\begin{array}{c}\text { Int } \leq \mathrm{VT} 1 \\
\mathrm{MHR} \leq 160\end{array}$ & $\begin{array}{c}\operatorname{lnt} \leq \mathrm{VT} 1 \\
\operatorname{lnt} \leq \mathrm{VT} 2 \\
\mathrm{MHR} \leq 160-170\end{array}$ & $\begin{array}{c}\text { Int } \leq \mathrm{VT} 1 \\
\text { Int } \leq \mathrm{VT} 2 \\
\text { Int } \leq \mathrm{MAP} 1 \\
\mathrm{MHR} \leq 170-180\end{array}$ & $\begin{array}{c}\text { Int } \leq \text { VT1 } \\
\text { Int } \leq \text { VT2 } \\
\text { Int } \leq \text { MAP2 } \\
\text { MHR } \leq 180-190\end{array}$ & \\
\hline Training type & & & $\begin{array}{l}\text { Speed endurance } \\
\text { Strength endurance } \\
\text { Tempo endurance } \\
\text { Running endurance } \\
\text { Power speed } \\
\text { Speed } \\
\text { Strength } \\
\text { Plyometric } \\
\text { Isodynamic }\end{array}$ & $\begin{array}{c}\text { Speed endurance } \\
\text { Strength endurance } \\
\text { Tempo endurance } \\
\text { Running endurance } \\
\text { Power speed } \\
\text { Speed } \\
\text { Strength } \\
\text { Plyometric } \\
\text { Isodynamic } \\
\text { Competition strategy }\end{array}$ & $\begin{array}{l}\text { Speed endurance } \\
\text { Strength endurance } \\
\text { Tempo endurance } \\
\text { Running endurance } \\
\text { Power speed } \\
\text { Speed } \\
\text { Strength } \\
\text { Plyometric } \\
\text { Isodynamic } \\
\text { Competition strategy }\end{array}$ & $\begin{array}{l}\text { Speed endurance } \\
\text { Strength endurance } \\
\text { Tempo endurance } \\
\text { Running endurance } \\
\text { Power speed } \\
\text { Speed } \\
\text { Strength } \\
\text { Plyometric } \\
\text { Isodynamic } \\
\text { Competition strategy }\end{array}$ & \\
\hline Season week & & & 18 & 18 & 16 & 15 & \\
\hline IMT $\quad 50 \%$ S-Index & & & $\begin{array}{c}30 \text { breaths morning and } \\
\text { evening }\end{array}$ & $\begin{array}{c}30 \text { breaths morning and } \\
\text { evening }\end{array}$ & $\begin{array}{c}30 \text { breaths morning and } \\
\text { evening }\end{array}$ & $\begin{array}{c}30 \text { breaths morning and } \\
\text { evening }\end{array}$ & \\
\hline $\begin{array}{l}\text { Measure at high } \\
\text { altitude }\end{array}$ & & $\begin{array}{l}\text { S-index, } \\
\mathrm{SpO}_{2}\end{array}$ & & & & & $\begin{array}{l}\text { S-index, } \\
\mathrm{SpO}_{2}\end{array}$ \\
\hline $\begin{array}{l}\text { Measure at low } \\
\text { altitude }\end{array}$ & & $1500 \mathrm{~m}$ & & & & & $1500 \mathrm{~m}$ \\
\hline days & & 1 & 7 & 7 & 7 & $7+2$ taiper & 1 \\
\hline Measure & & pre & & & & & post \\
\hline
\end{tabular}

Table 2: IMT plan and training system R2M (this is an acronym for running at middle distance to marathon) at altitude. Quantities of training intensity (Int), maximal aerobic power (MAP), Maximal heart rate (MHR), first Ventilatory threshold (VT1) and second Ventilatory threshold (VT2) [1,44-48].

\begin{tabular}{|c|c|c|c|c|}
\hline & \multicolumn{2}{|c|}{ CON group } & \multicolumn{2}{c|}{ EXP group } \\
\hline indexes & PRE & POST & PRE & POST \\
\hline S-Index $\left(\mathrm{cm} \mathrm{H}_{2} \mathrm{O}\right)$ & $110 / 23 \pm$ & $10 / 8 \pm$ & $22 \pm 122 / 45$ & $18 / 35 \pm$ \\
& $22 / 3$ & $130 / 60$ & & $141 / 54$ \\
\hline $\mathrm{PIF}(\mathrm{L} / \mathrm{sec})$ & $1 / 14 \pm 5 / 98$ & $0 / 62 \pm 6 / 19$ & $1 / 14 \pm 6 / 78$ & $0 / 96 \pm 6 / 97$ \\
\hline Volume (liter) & $0 / 63 \pm 2 / 83$ & $1 / 02 \pm 2 / 99$ & $0 / 59 \pm 3 / 54$ & $0 / 44 \pm 3 / 54$ \\
\hline $\mathrm{SpO}_{2}(\%)$ & $0 / 32 \pm 94 / 30$ & $0 / 22 \pm 94 / 33$ & $0 / 24 \pm 94 / 35$ & $0 / 62 \pm 94 / 58$ \\
\hline Performance 1500 m & $0 / 18 \pm$ & $0 / 30 \pm$ & $0 / 20 \pm$ & $0 / 50 \pm$ \\
(min) & $4: 03: 29$ & $3: 56: 52$ & $4: 01: 20$ & $3: 52: 31$ \\
\hline
\end{tabular}

Table 3: Pre- and post-training characteristics in experiment and in control group.

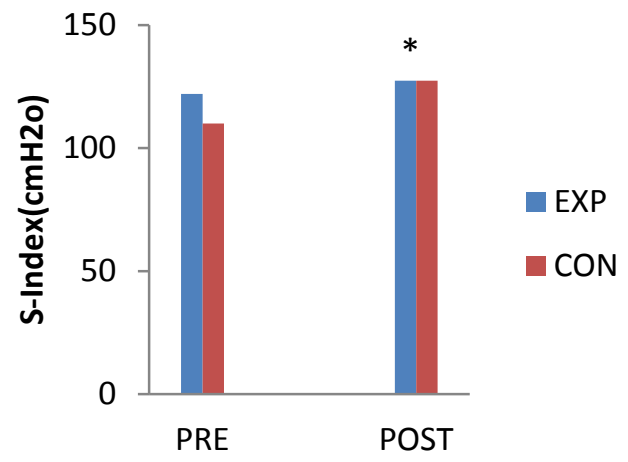

Figure 1: Mean pre- to post-training S-Index for EXP and CON groups.

*significant post-training S-Index increase in, EXP $(p=0.01)$. Post-training S-Index Significantly increased in EXP $(p=0.05)$

Not being exposed to hypoxic condition probably lead to minute hyperventilation as primary response. Consequently peripheral chemoreceptors in respiratory system may cope with hypoxia. However respiratory organs are ultra-structured against any applied changes in

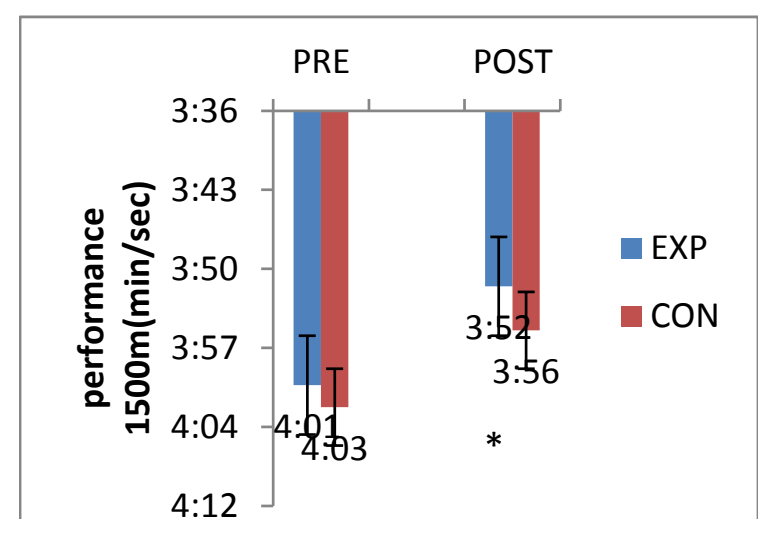

Figure 2: Mean pre- to post-training $1500 \mathrm{~m}$ performance times for EXP and CON groups.

*significant post-training increase in performance $(p=0.00)$. Post-training performance significantly increased in EXP group $(p=0.05)$.

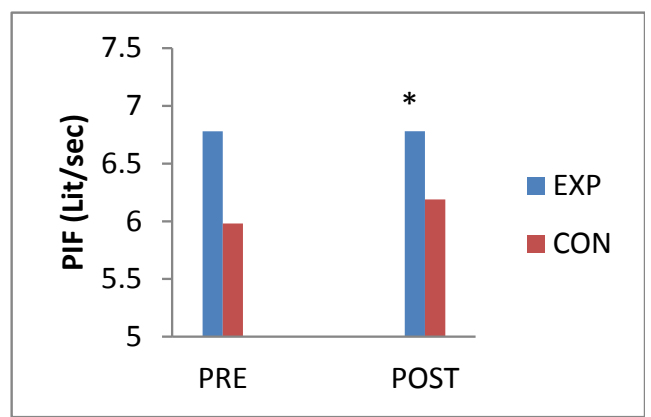

Figure 3: Mean pre- to post-training PIF for EXP and CON groups.

*significant post-training change in PIF, $(p=0.02)$. PIF significant increase post-training change in EXP group $(p=0.05)$. 
different environmental conditions. $\mathrm{SpO}_{2}$ reduction due to climbing from sea level will decrease $\mathrm{SaO}_{2}[10]$. Long alkalosis that occurs in high altitude as well as increasing 2,3-diphosphoglycerate (dpg) concentration won't lead to complete respiratory compensation, but will navigate the balance between extra oxygen loading in lung, oxygen tissue proliferation and ultimately minimum $\mathrm{pH}$ disturbance. IMT may modify natural hyper-ventilation in response to hypoxia through such process [10-12].

In our study IMT in hypoxic condition made significant difference in pre-test and post-test PIF among experimental group (3.5\%). Haung (2003) has also reported PIF increase (45\%) after eleven weeks IMT. This higher percentage surely is related to longer training period. We did not find any significant difference in PIF between both groups under hypoxic condition which is inconsistent with results of Mazzeo and Fulco [35], and Brown et al. [33]. This contradiction might be due to training protocol or even we did not set training protocol specifically for endurance runners.

Our results show significant decrease in $1500 \mathrm{~m}$ between-group running time among experimental group (3.65\%). Astinchap et al. [36] and Behparvar (2015) also have reported that IMT in hypoxic condition is effective in $25 \mathrm{~m}$ length amongst female swimmers. But this effect was not significant in $50 \mathrm{~m}$ and $100 \mathrm{~m}$ length. One of the probable reasons for this outcome may be depended on stronger respiratory system in swimmers [36]. Likewise, McConnell and Romer [37] have shown that IMT improves time trail performance, accelerates recovery period, decreases lactate blood level and delays muscles fatigue [37-44]. Verges et al. [45] have shown that exposure to hypoxia lead to improve endurance performance, The mechanism of the improvement appear to be a stimulation of erythropoiesis leading to an apparent increase in oxygen delivery to peripheral tissues as evidenced by a near doubling of plasma erythropoietin concentration, a rise in soluble transferrin receptor concentration and increase in hemoglobin concentration and hematocrit with chronic exposure to altitude on return to sea level [45]. Martin et al. (2012) have shown a significant effect of BMI on the performance of male long distance runners. BMI influenced the performance, yielding a positive correlation with the race time, the speed being higher in athletes from the underweight to the overweight [46]. In fact, chronic exposure to reduced partial pressure of oxygen as it is the case at high altitude, decreases arterial oxygen saturation, provoking shifts in substrate metabolism. This increases the difficulty for the body to use oxidative phosphorylation to produce the energy needed for endurance exercise; the glycolytic pathway is therefore favored rather than other catabolic pathways, including fat catabolism for energy production, because it has the lowest oxygen cost [47].

It should be noted that unlike swimming, there is no perceived exertion throughout the running. Utilizing IMT under hypoxia can reduce perceived exertion and improve performance without any side effects on respiration indexes. Some reports admit that time trial performance and maximal oxygen uptake $\left(\mathrm{VO}_{2} \max \right)$ get better amongst cyclists after IMT $[37,38]$. The significant increase of running performance after training in high altitude is not consistence with Siebenmann et al. [39] findings. They assessed LHTL in sixteen male endurance cyclists and did not observe any significant difference in $26 \mathrm{~km}$ time trial performance among them under normoxic condition [39].

Finally, based on current literatures, $1500 \mathrm{~m}$ performance improve, S-Index and PIF have considerably enhanced among runners after returning from higher altitude to lower levels.

\section{Conclusion}

Achieving better physiological condition for athletics in each sport field is the main reason of specific training and IMT, explicit training protocol for each field can be helpful for researchers. Even though $1500 \mathrm{~m}$ performance, PIF and S-Index were improved in this study but there was no exclusive change in $\mathrm{SpO}_{2}$ as it was primarily expected. Therefore deploying specific tailored training program for runners can be recommended for future studies in order to obtain $\mathrm{SpO}_{2}$ alteration precisely. So coaches should pay more attention to training features in accordance with requirement of each sport field. For endurance runners more studies on IMT effectiveness might be considered because they need more ventilation for improving their performances.

\section{Acknowledgement}

The authors thank Mazandaran University Laboratory and Power breathe company in Iran for facilitating space used to gather relevant information for this article. This work received no specific grant from any funding agency whatsoever.

\section{References}

1. HajGhanbari B, Yamabayashi C, Buna TR, Coelho JD, Freedman KD, et al. (2013) Effects of respiratory muscle training on performance in athletes: a systematic review with meta-analyses. J Strength Cond Res 27: 1643-1663.

2. Harms CA, Wetter TJ, McClaran SR, Pegelow DF, Nickele GA, et al. (1998) Effects of respiratory muscle work on cardiac output and its distribution during maximal exercise. J Appl Physiol 85: 609-618.

3. Legrand R, Marles A, Prieur F, Lazzari S, Blondel N, et al. (2007) Related trends in locomotor and respiratory muscle oxygenation during exercise. Med Sci Sports Exerc 39: 91-100.

4. Johnson MA, Sharpe GR, Brown PI (2007) Inspiratory muscle training improves cycling time-trial performance and anaerobic work capacity but not critical power. Eur J Appl Physiol 101: 761-770.

5. Sheel AW (2002) Respiratory muscle training in healthy individuals: physiological rationale and implications for exercise performance. Sports Med 32: 567-581.

6. Illi SK, Held U, Frank I, Spengler CM (2012) Effect of respiratory muscle training on exercise performance in healthy individuals: a systematic review and metaanalysis. Sports Med 42: 707-724.

7. Dempsey JA, Romer L, Rodman J, Miller J, Smith C (2006) Consequences of exercise-induced respiratory muscle work. Respir Physiol Neurobiol 151: 242250.

8. Hill JM (2000) Discharge of group IV phrenic afferent fibers increases during diaphragmatic fatigue. Brain Res 856: 240-244.

9. Derchak PA, Sheel AW, Morgan BJ, Dempsey JA (2002) Effects of expiratory muscle work on muscle sympathetic nerve activity. J Appl Physiol (1985) 92 1539-1552.

10. Harms CA (2007) Insights into the role of the respiratory muscle metaboreflex. J Physiol 584: 711

11. Witt JD, Guenette JA, Rupert JL, McKenzie DC, Sheel AW (2007) Inspiratory muscle training attenuates the human respiratory muscle metaboreflex. Physiol 584: 1019-1028.

12. Bisschop A, Gayan-Ramirez G, Rollier H, Gosselink R, Dom R, et al. (1997) Intermittent inspiratory muscle training induces fiber hypertrophy in rat diaphragm. Am J Respir Crit Care Med 155: 1583-1589.

13. Randall W (2011) Application of altitude/hypoxic training by elite athlete's. Med Sci Sports Exerc 88: 5202

14. Álvarez-Herms J, Julià-Sánchez S, Corbi F, Pagès T, Viscor G (2014) Anaerobic performance after endurance strength training in hypobaric environment. Sci Sports, 29: 311-318.

15. Wolski LA, McKenzie DC, Wenger HA (1996) Altitude training for improvements in sea level performance. Is the scientific evidence of benefit? Sports Med 22 251-263.

16. Meeuwsen T, Hendriksen IJ, Holewijn M (2001) Training-induced increases in sea-level performance are enhanced by acute intermittent hypobaric hypoxia Eur J Appl Physiol 84: 283-290.

17. Terrados N, Melichna J, Sylvén C, Jansson E, Kaijser L (1988) Effects of training at simulated altitude on performance and muscle metabolic capacity 
Citation: Roohollah MM, Shadmehr M (2016) The Effect of an Inspiratory Muscle Training Period at High Altitude on Arterial Oxygen Saturation and Performance of Iran's National Team Endurance Runners. J Pulm Respir Med 6: 356. doi:10.4172/2161-105X.1000356

in competitive road cyclists. Eur J Appl Physiol Occup Physiol 57: 203-209.

18. Bailey DM, Davies B (1997) Physiological implications of altitude training for endurance performance at sea level: a review. Br J Sports Med 31: 183-190.

19. Vogt M, Puntschart A, Geiser J, Zuleger C, Billeter R, et al. (2001) Molecular adaptations in human skeletal muscle to endurance training under simulated hypoxic conditions. J Appl Physiol 91: 173-182.

20. Lomax M (2010) Inspiratory muscle training, altitude, and arterial oxygen desaturation: a preliminary investigation. Aviat Space Environ Med 81: 498501

21. Etheridge T, Atherton PJ, Wilkinson D, Selby A, Rankin D, et al. (2011) Effects of hypoxia on muscle protein synthesis and anabolic signaling at rest and in response to acute resistance exercise. Am J Physiol Endocrinol Metab 301 : E697-E702.

22. Downey AE, Chenoweth LM, Townsend DK, Ranum JD, Ferguson CS, et al. (2007) Effects of inspiratory muscle training on exercise responses in normoxia and hypoxia. Respir Physiol Neurobiol 156: 137-146.

23. Edwards AM, Wells C, Butterly R (2008) Concurrent inspiratory muscle and cardiovascular training differentially improves both perceptions of effort and $5000 \mathrm{~m}$ running performance compared with cardiovascular training alone. $\mathrm{Br}$ J Sports Med 42: 823-827.

24. Volianitis S, McConnell AK, Koutedakis Y, McNaughton L, Backx K, et al. (2001) Inspiratory muscle training improves rowing performance. Med Sci Sports Exerc 33: 803-809.

25. Romer LM, McConnell AK, Jones DA (2002) Effects of inspiratory muscle training on time-trial performance in trained cyclists. J Sports Sci 20: 547-562.

26. Suzuki S, Sato M, Okubo T (1995) Expiratory muscle training and sensation of respiratory effort during exercise in normal subjects. Thorax 50: 366-370.

27. Edwards AM, Cooke CB (2004) Oxygen uptake kinetics and maximal aerobic power are unaffected by inspiratory muscle training in healthy subjects where time to exhaustion is extended. Eur J Appl Physiol 93: 139-144.

28. McConnell AK (2009) Respiratory muscle training as an ergogenic aid. J Exerc Sci Fit 7: S18-S27.

29. Kilding AE, Brown S, McConnell AK (2010) Inspiratory muscle training improves 100 and 200 m swimming performance. Eur J Appl Physiol 108: 505-511.

30. Nicks CR, Morgan DW, Fuller DK, Caputo JL (2009) The influence of respiratory muscle training upon intermittent exercise performance. Int J Sports Med 30: 16-21.

31. Wylegala JA, Pendergast DR, Gosselin LE, Warkander DE, Lundgren CE (2007) Respiratory muscle training improves swimming endurance in divers Eur J Appl Physiol 99: 393-404.

32. Brown PI, Johnson MA, Sharpe GR (2014) Determinants of inspiratory muscle strength in healthy humans. Respir Physiol Neurobiol 196: 50-55.
33. Brown PI, Sharpe GR, Johnson MA (2010) Loading of trained inspiratory muscles speeds lactate recovery kinetics. Med Sci Sports Exerc 42: 1103-1112.

34. Brown PI, Sharpe GR, Johnson MA (2012) Inspiratory muscle training abolishes the blood lactate increase associated with volitional hyperpnoea superimposed on exercise and accelerates lactate and oxygen uptake kinetics at the onset of exercise. Eur J Appl Physiol 112: 2117-2129.

35. Mazzeo RS, Fulco CS (2006) Physiological systems and their responses to conditions of hypoxia. ACSM's Adv Exerc Physiol 42: 564-590.

36. Astinchap A, Nasser B, Tadibi V (2015) The effect of inspiratory muscle training for six weeks (IMT) on swimming speed. J Physiol Sports Manag 7: 51.

37. McConnell AK, Romer LM (2004) Respiratory muscle training in healthy humans: resolving the controversy. Int J Sports Med 25: 284-293.

38. McMahon ME, Boutellier U, Smith RM, Spengler CM (2002) Hyperpnea training attenuates peripheral chemosensitivity and improves cycling endurance. J Exp Biol 205: 3937-3943

39. Siebenmann $C$, Robach $\mathrm{P}$ Jacobs RA, Rasmussen $\mathrm{P}$ Nordsborg $\mathrm{N}$, et al. (2012) "Live high-train low" using normobaric hypoxia: a double-blinded, placebo-controlled study. J Appl Physiol 112: 106-117.

40. Álvarez-Herms J, Julià-Sánchez S, Gatterer H, Viscor G, Burtscher M (2015) Differing Levels of Acute Hypoxia Do Not Influence Maximal Anaerobic Power Capacity. Wilderness Environ Med 26: 78-82.

41. Fudge BW, Pringle JS, Maxwell NS, Turner G, Ingham SA, et al. (2012) Altitude Training for Elite Endurance Performance. Curr Sports Med Rep 17: 1103-1112.

42. Di Michele R, Merni F (2014) The concurrent effects of strike pattern and ground-contact time on running economy. J Sci Med Sport 17: 414-418.

43. Saunders PU, Pyne DB, Telford RD, Hawley JA (2004) Factors affecting running economy in trained distance runners. Sports Med 34: 465-485.

44. Le Meur Y, Hausswirth C, Mujika I (2012) Tapering for competition: A review. Sci Sports 27: 77-87.

45. Verges S, Bachasson D, Wuyam B (2010) Effect of acute hypoxia on respiratory muscle fatigue in healthy humans. Respir Res 11: 109.

46. Salah MA, Verla VS, Tonga C (2012) Anthropometric and Hemodynamic Profiles of Athletes and Their Relevance to Performance in the Mount Cameroon Race of Hope. Asian J Sports Med 3: 99-104.

47. Benso A, Broglio F, Aimaretti G, Lucatello B, Lanfranco F, et al. (2007) Endocrine and metabolic responses to extreme altitude and physical exercise in climbers. Eur J Endocrinol 157: 733-740. 